\title{
RODA DE CONVERSA: RELATO DA EXPERIÊNCIA DO MOVIMENTO DE MULHERES CAMPONESAS NO ENFRENTAMENTO À VIOLÊNCIA CONTRA A MULHER NO ASSENTAMENTO ITAMARATI
}

\author{
TALKING WHEEL: REPORTING THE EXPERIENCE OF MOVEMENT OF \\ PEASANT WOMEN IN FACING VIOLENCE AGAINST WOMEN IN ITAMARATI \\ SETTLEMENT
}

\author{
Mariza Madalena Dahmer ${ }^{1}$ \\ Olga Manosso ${ }^{2}$ \\ Sederli Bombarda Sobrinho 3
}

Resumo: O presente artigo relata e analisa a partir da Roda de Conversa a importância da organização coletiva das mulheres, da formação e da luta no enfrentamento à violência. A metodologia foi pautada a luz dos referenciais teóricos que abordam a violência contra a mulher, pelas questões de gênero e pelos registros das atividades realizadas no período de fevereiro de 2017 a dezembro de 2018, nas listas de presença e pelo arquivo fotográfico da Roda de Conversa. Foi levantado ainda o número de atendimentos psicológicos e jurídicos realizados nesse período pelo Centro de Atendimento à Mulher (CAM) do município de Ponta Porã, MS. Os resultados demonstraram que as ações da Roda contribuíram no enfrentamento a violência, no conhecimento das leis e nas discussões de gênero junto à comunidade, evidenciando a importância da participação coletiva, da resistência e da luta por políticas públicas de combate à violência e que promovam a igualdade gênero, especialmente no meio rural, onde há inúmeras dificuldades de acesso à rede de enfrentamento à violência.

Palavras-chave: Participação coletiva, emancipação, luta contra à violência.

Abstract: This article reports and analyzes, based on the project đ́Roda de ConversaQ̂ the relevance of the women collective organization, qualification and struggle to confront violence. The methodology was guided by the theoretical references that address the violence against women, gender issues and information gathering from the records inherent to the activities carried out from February 2017 to December 2018 in the presence lists and photographic archives fromđ́Roda de ConversaôIt has also approached the number of psychological and legal attendances performed by the ócentro de Atendimento à Mulher (CAM)ôfrom Ponta Porã, MS.

The results demonstrated that the actions from đ́Rodaôcontributed in the combat against violence, legal knowledge and gender discussions with the community, evidencing the

\footnotetext{
${ }^{1}$ Agente de Desenvolvimento Rural na Agência de Desenvolvimento Agrário e Extensão Rural de Mato Grosso do Sul - AGRAER

${ }^{2}$ Graduada em História pela Universidade de Caxias do Sul, Caxias do Sul/RS

${ }^{3}$ Graduada em Ciências Biológicas pelas Faculdades Integradas de Ponta Porã, MS - FAMAG
}

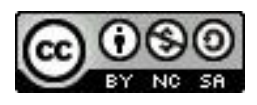


importance of collective participation, resistance and fight for public politics that struggle violence and promote gender equality, specially in rural areas, where there are countless difficulties in accessing the network to face violence.

Keywords: Collective participation, emancipation, fight against violence.

\section{INTRODUÇÃO}

A violência contra a mulher é um fenômeno vivenciado pelas mulheres em todos os espaços sociais. Entretanto, no espaço rural essa problemática se agrava em função das dificuldades de acesso à Rede de Enfrentamento a Violência Contra à Mulher ${ }^{4}$, que são instaladas no espaço urbano. A distância entre o espaço rural e o espaço urbano aliada a falta de recurso financeiro constitui-se em elementos que se somam a gama de problemas enfrentados pelas mulheres em situação de violência, inclusive as desigualdades nas relações de gênero configuram-se em um obstáculo a mais a ser superado pelas mulheres do campo, uma vez que as desigualdades interferem e violam os direitos das mulheres, invisibilizando o trabalho produtivo, a geração de renda, a autonomia e sua atuação enquanto sujeito.

Nesse sentido, o Movimento de Mulheres Camponesas ${ }^{5}$ (MMC), constituído enquanto movimento no Assentamento Itamarati desde o ano de 2003 com o lema: ñBasta de Violência Contra a Mulherò desenvolve suas ações alicerçadas no processo de organização, de formação e de luta objetivando que as mulheres reconheçam as formas de violências vivenciadas, para que possam romper o ciclo da violência. Assim, o Movimento de Mulheres Camponesas vem desenvolvendo ações que possam promover a ressignificação das relações no assentamento, a valorização e a autonomia das mulheres. Pois é através da resistência e da luta organizada que a mulher garante sua afirmação enquanto ser social e agente transformador da sociedade (PALUDO, 2009).

A partir da organização coletiva das mulheres, das vivências no processo de organização, formação e luta realizadas pelo Movimento das Mulheres Camponesas

\footnotetext{
${ }^{4}$ A Lei Maria da Penha (Lei, n. 11.340/2006) define a violência contra a mulher como qualquer ação ou omissão baseada no gênero que lhe cause morte, lesão ou sofrimento físico, sexual ou psicológico e dano moral ou patrimonial. Também prevê a criação de serviços especializados, como os que integram a Rede de Enfrentamento à Violência contra a Mulher, compostos por instituições de segurança pública, justiça, saúde, e da assistência social.

${ }^{5} \mathrm{O}$ Movimento de mulheres Camponesas ï MMC é organizado, composto e dirigido exclusivamente por mulheres camponesas de diversos Estados do Brasil. Através deste movimento as mulheres vêm desempenhando uma árdua luta pela conquista de direitos, igualdade, autonomia e pela superação da violência (ANMC, 2008).
} 
(MMC), a violência contra as mulheres se apresentou como uma problemática de extrema gravidade, exigindo ações continuadas para se encontrar saídas para a sua superação, sobretudo, considerando os muitos fatores que contribuem para a violência contra as mulheres como a impunidade dos agressores, o silêncio das mulheres agredidas, a ideia construída sobre a inferioridade das mulheres, a transformação das vítimas em culpadas, dentro outros. E foi no bojo dessa discussão; que nasceu a Roda de Conversa do Assentamento Itamarati, a qual servirá de subsídio para as análises aqui realizadas.

O Assentamento Itamarati encontra-se localizado no município de Ponta Porã, Estado de Mato Grosso do Sul, é considerado o maior Assentamento Rural da América Latina, foi constituído em duas etapas distintas; por isso, denominado de Assentamento Itamarati $\mathrm{I}^{6} \mathrm{e} \mathrm{II}^{7}$. As duas partes totalizam 2.835 (duas mil e oitocentos e trinta e cinco) famílias assentadas. As relações tanto familiares, quanto às relações desenvolvidas no âmbito da comunidade, são centradas na figura masculina, que ñrepresentaòos interesses do conjunto e detém o poder de decisão. Estabelecendo assim, uma hierarquia de gênero e geração pautada no poder dos homens sobre as mulheres. Essa realidade despertou para a necessidade de se fortalecer através da organização coletiva, ampliando as discussões no sentido de construir autonomia e visibilidade ao trabalho da mulher na agricultura familiar, pois as atividades produtivas desenvolvidas por elas na unidade familiar têm importante significado, inclusive econômico.

A Roda de Conversa foi constituída fundamentada em processo de diálogos, estudos e reflexões sobre a violência vivenciada pelas mulheres no espaço familiar, no âmbito do Assentamento Itamarati I e II . A experiência teve início em meados de 2015, a partir de iniciativa do Movimento de Mulheres Camponesas (MMC), em parceria com a Associação Assentamento Itamarati Gerando Vidas (AAIGV), a agência de

\footnotetext{
${ }^{6}$ Assentamento Itamarati I foi implantado no ano de 2002, em uma área de vinte e cinco mil e cem hectares, onde foram assentadas 1.143 famílias, divididas em quatro subáreas pertencentes aos seguintes Movimentos Sociais: o Movimento dos Trabalhadores Rurais Sem Terra (MST) com 320 famílias; a Central Única dos Trabalhadores (CUT) com 280 famílias; a Federação dos Trabalhadores na Agricultura (FETAGRI) com 393 famílias; e a Associação dos Moradores e Funcionários da Fazenda Itamarati (AMFFI) com 150 famílias, totalizando 1.143 famílias (MATO GROSSO DO SUL, 2003).

${ }^{7} \mathrm{O}$ Assentamento Itamarati II foi implantado em 2004 onde foram assentadas 1.692 famílias conduzidas e organizadas pelos movimentos sociais sendo: 588 famílias da Federação dos Trabalhadores na Agricultura (FETAGRI), 568 famílias do Movimento dos Trabalhadores Sem Terra (MST), 270 famílias da Central Única dos Trabalhadores (CUT), 150 famílias da Federação da Agricultura Familiar (FAF) e 116 famílias da associação denominada Funcionários Associados da Fazenda Itamarati (FAFI) (FUNDAÇÃO CÂNDIDO RONDON).
}

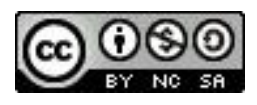


Desenvolvimento Agrário e Extensão Rural (AGRAER), o Banco Comunitário Ita $^{8}$ e a comunidade.

A Roda de Conversa foi constituída com o objetivo de contribuir no enfrentamento à violência contra a mulher no assentamento Itamarati. A modalidade de Roda de Conversa foi escolhida por se tratar de um processo metodológico participativo, que envolve e acolhe as mulheres, no sentido de estimular o reconhecimento das formas de violência contra as mulheres e, sobretudo, no sentido de buscar meios que contribuam no combate e na prevenção desse fenômeno, que causa sofrimento físico, psicológico e emocional à mulher, consequentemente, aos filhos e a família como um todo, constituindo-se em grave violação dos direitos humanos.

As demandas que surgiram já nos primeiros encontros da Roda de Conversa com as mulheres assentadas e demais moradoras, evidenciaram a necessidade de se buscar a parceria com o Centro de Atendimento à Mulher ${ }^{9}$ (CAM) do município de Ponta Porã, em função de sua estrutura para o enfrentamento à violência contra a mulher, composta por equipe profissional multidisciplinar para tratar a questão da violência contra a mulher e, principalmente, para se viabilizar atendimento jurídico e psicológico dentro do próprio assentamento às mulheres em situação de violência. Essa parceria foi constituída em 2016 e segue atualmente com muito êxito.

Nessa perspectiva, apresentamos os resultados alcançados no combate e prevenção à violência contra a mulher no espaço da Roda de Conversa do Assentamento Itamarati no período de fevereiro de 2017 a dezembro de 2018 com o objetivo de compartilhar essa valorosa experiência.

A metodologia constituiu-se da fundamentação teórica a luz dos referenciais teóricos que abordam a problemática da violência contra a mulher e as questões de gênero

\footnotetext{
${ }^{8}$ Banco Comunitário de Desenvolvimento é um sistema integrado de crédito, produção, comércio e consumo, que promove o desenvolvimento local, e busca a melhoria da qualidade de vida, na perspectiva de Economia Solidária. Em atividade no Assentamento Itamarati desde o ano de 2012, através da organização dos produtores familiares assentados disponibilizando linhas de créditos que visam potencializar as iniciativas de produção com a perspectiva de desenvolvimento local da comunidade agregado as práticas de ações solidárias sob o aval da comunidade. A comunidade é a proprietária e gestora do Banco e responsável por definir as linhas de crédito, taxa de juros, finalidades, prazos de devolução e a própria aprovação de liberação dos créditos estabelecidos na Política de Crédito do Banco Ita construída em conjunto com a comunidade.

${ }^{9} \mathrm{O}$ Centro de Atendimento à Mulher (CAM) de Ponta Porã, MS é um espaço de atendimento psicológico, social, orientação e encaminhamento jurídico à mulher em situação de violência, que proporciona o atendimento e acolhimento necessário à superação da situação de violência ocorrida, contribuindo para o fortalecimento da mulher e o resgate da sua cidadania.
} 
que contribuem com a violência, pautada na concepção de Gil (2010) e da coleta de informações a partir dos registros escritos inerentes as atividades realizadas no período de fevereiro de 2017 a dezembro de 2018, junto as mulheres, nas listas de presença e no arquivo fotográfico da Roda de Conversa, bem como nos registros de atendimentos psicológicos e jurídicos realizados pela equipe profissional do Centro de Atendimento à Mulher (CAM) do município de Ponta Porã, junto as mulheres do assentamento Itamarati.

A abordagem da violência contra as mulheres no espaço da Roda de Conversa do Assentamento Itamarati engloba a dimensão da desigualdade de gênero no contexto da construção social, política e cultural. Considerando que o diálogo e o estudo constituem-se em importantíssimas ferramentas para compreensão, enfrentamento e desconstrução do processo histórico de desigualdade e invisibilidade.

A dinâmica metodológica solidária, democrática e participativa construída na Roda de Conversa, tem permitido discutir a violência a partir da dimensão de gênero. $\mathrm{O}$ enfrentamento pelo fim da violência contra a mulher caminha junto com o enfrentamento ao fim das desigualdades de gênero, e as mulheres do campo enfrentam com mais intensidade as relações desiguais de gênero, tanto no espaço familiar, quanto nos espaços coletivos, nesse sentido, Menegat (2008, p. 05) destaca ña existência de uma estrutura social que ainda guarda hierarquias de poder, com importância social diferenciada entre homens e mulheres no conjunto socialò, ou seja, a mulher mesmo participando ativamente dos processos produtivos, e dos espaços de comercialização é vista e colocada ainda na categoria de ajudante e como a única responsável pelo trabalho reprodutivo.

De acordo com Machado (2000) o processo de enfrentamento à violência contra a mulher exige a compreensão do conceito de gênero, pois a nossa sociedade é extremamente marcada pelas diferenças de gênero. Nesse sentido, a compreensão do fenômeno da violência no cotidiano das relações, inclusive nas relações de trabalho no assentamento Itamarati têm sido construídas, sobretudo, a partir das vivências das mulheres, relacionando-as com os fatores que são determinantes para a desigualdade de gênero e consequentemente para sua desconstrução.

A Roda de Conversa constitui-se em de espaço de diálogo compartilhado e espontâneo que oportuniza a abertura da problemática da violência e o acesso ao atendimento jurídico e psicológico. O Centro de Atendimento à Mulher assessora em termos legais, a solução dos conflitos existentes, bem como, a seguridade de seus direitos, 
muitas vezes suprimidos pela dominação masculina, que desconsidera sua participação no processo produtivo, associando assim a violência de gênero e à violência doméstica.

Relatar esta problemática exige coragem, confiança e a segurança de que as ações não se limitam ao âmbito do discurso, e no espaço da Roda de Conversa a mulher sente-se acolhida, fortalecida e protegida, para dar os primeiros passos no sentido de romper definitivamente com ciclo de violência no qual está submetida.

Neste contexto, a espaço de discussão tornou-se um importante instrumento no estabelecimento de vínculos, baseados na confiança, no respeito, na solidariedade das mulheres que vivenciaram situações semelhantes, mas que não desistiram de lutar por sua liberdade e hoje buscam através do diálogo contribuir para que outras companheiras possam romper esse ciclo.

\section{DIALOGANDO A VIOLÊNCIA CONTRA AS MULHERES NA PERSPECTIVA DE DESIGUALDADE DE GÊNERO NO ÂMBITO DA RODA DE CONVERSA}

O sistema de gênero define a vida nas sociedades a partir da linguagem, dos símbolos, das instituições e hierarquias da organização social, da representação política e do poder. Nesse sentido, Menegat (2008, p.5) aborda a hierarquia com papéis diferenciados de poder destacando que ño meio rural essa hierarquia parece ter um ritmo mais lento para a superação dessa diferençaò. O papel da mulher na sociedade historicamente é regulado pelo âmbito biológico e social, que por sua vez, também são reguladores das desigualdades de gênero e perpetuados de geração em geração a valoração do masculino sob o feminino. Ou seja, o conceito de gênero entendido como construção cultural, fundamentado na diferença sexual (BRASIL, 2012).

Ao percorrer a história constata-se que a mulher sempre teve seu papel diminuído na sociedade. Infelizmente, ainda nos dias atuais, em todas as partes do mundo, em todos os espaços, em todas as classes sociais, ainda é marcante a ñsupostaò inferioridade feminina, pensamento este, historicamente construído e perpetuado. Paludo (2009, p. 86) destaca que ña história do Brasil e da humanidade, como um todo, é propagada através de uma visão parcial, isto é, através de um olhar próprio da sociedade patriarcalò. 
Os papéis preestabelecidos como atividades próprias dos sexos foram internalizados pelos sujeitos sociais e ao reproduzirem determinadas práticas e valores, os sujeitos permanecem agindo ainda que de maneira inconsciente, para a manutenção do modelo patriarcal e é nesse contexto de desigualdade hierárquica entre os papéis de gênero que se desenvolvem as diversas formas de violência contra a mulher. As formas de violência vivenciadas pelas mulheres guardam intrínseca ligação com os papéis de gênero preestabelecidos, no qual o homem figura no centro do poder e a mulher na condição de submissão (CHAUI, 1984).

$\mathrm{Na}$ Roda de Conversa tem se ampliado os debates e reflexões em torno do conceito violência contra a mulher e violência de gênero. Considerando que estes dois conceitos impactam a vida das mulheres que residem no campo em todas as esferas, nesse sentido, o MMC (2018) registra que:

\footnotetext{
No rural, uma forma de violência que é muito naturalizada é a sobrecarga de trabalho, todos trabalham na roça, todos lidam com os animais e o trabalho produtivo que existir na unidade de produção da família, mas, na maioria das vezes, apenas as mulheres realizam o trabalho reprodutivo e de cuidados, o que coloca sobre ela uma enorme sobrecarga de trabalho (p.21).
}

O exposto deixa claro que esta forma de violência envolvendo relações de gênero e poder, normalmente é naturalizada. Na Roda de Conversa do assentamento Itamarati esta temática tem permeado o debate coletivo, fundamentado na bibliografia produzida pelo Movimento de Mulheres Camponesas (MMC-Brasil). O dinamismo da Roda ao abordar as discussões em torno da violência utiliza-se de ferramentas didáticas como: panfletos, publicações, livros, revistas, jornais, além de recursos audiovisuais que ilustrem situações cotidianas nas quais a violência encontra-se inserida e que em muitos casos passam despercebidas, ou ainda, são confundidas com cuidado, amor, ciúmes, sentimento de posse, entre outros. A abordagem da temática violência é sempre permeada pela interação, respeito e sigilo entre as participantes, através do diálogo, relatos, depoimentos e de troca de experiência.

A violência contra as mulheres e a violência de gênero se evidenciam nos relatos, nos depoimentos, no acolhimento da Roda de Conversa, que gradativamente construiu a confiança e o respeito entre as participantes tornando-se espaço de compartilhamento da dor sofrida em situações de abuso, vivências de violência e violação dos direitos. 
As temáticas abordadas no espaço da Roda de Conversa dialogam a partir do contexto vivenciado e das inquietações da vida cotidiana buscando a compreensão dos tipos de violência ${ }^{10}$ aos quais as mulheres estão submetidas, pautadas na tríade: perceber, refletir e agir para modificar enquanto movimento coletivo, político e democrático de libertação, movimento esse, respaldado na Pedagogia da autonomia de Paulo Freire (1996).

\section{A DINÂMICA METODOLÓGICA DA RODA DE CONVERSA DO} ASSENTAMENTO ITAMARATI

A Roda de Conversa é realizada desde sua constituição no ano de 2015 de fevereiro a dezembro em todas as últimas quartas-feiras de cada mês. Acontece no espaço denominado de Centro Social pertencente a Associação Assentamento Itamarati Gerando Vidas (AAIGV). O processo de mobilização, de organização e de confecção de materiais para as atividades realizadas no espaço da Roda de Conversa são viabilizados pelos grupos parceiros: Movimento de Mulheres Camponesas (MMC), Agência de Desenvolvimento Agrário e Extensão Rural (AGRAER) e Banco Comunitário Ita.

Há ainda outros grupos que contribuem para enriquecer os debates, as atividades e as ações realizadas na Roda de Conversa como: A Comissão da Mulher advogada da OAB de Ponta Porã/MS com a pauta dos direitos; o Programa Mulher Segura $^{11}$ (PROMUSE) da Polícia Militar/MS, com atuação dentro do Assentamento Itamarati, o Instituto Brasileiro de Geografia e Estatística (IBGE) abordando os avanços na conquista dos direitos das mulheres.

\footnotetext{
${ }^{10}$ Dentre as modalidades de violência contra a mulher Brasil (2012) destaca: A violência física é qualquer ação ou omissão que ofenda a integridade física da mulher, quando. A violência sexual é qualquer ação que obrigue a mulher a manter contato sexual, físico ou verbal através do uso da força, intimidação, coerção, chantagem, suborno, manipulação, ameaça ou qualquer outro meio que anule ou limite a vontade pessoal, no casamento ou em outros relacionamentos. A violência psicológica é qualquer ação ou omissão destinada a controlar as ações, comportamentos, crenças e decisões da mulher, por meio de intimidação, manipulação, ameaça, humilhações, ameaça de agressão, privação da liberdade. Violência Patrimonial ou econômica pode ser caracterizada como qualquer ação de omissão que implique dano, perda, subtração, destruição ou retenção de objetos, documentos pessoas, bens e valores. Violência Moral de um modo geral é concomitante com a violência psicológica. Diz respeito a qualquer ação destinada a caluniar, difamada ou injuriar a honra ou a reputação da mulher.

${ }^{11}$ As mulheres do Mato Grosso do Sul contam com uma ajuda a mais no combate à violência doméstica: ñMulher Seguraò, da Polícia Militar. O Programa proporciona um atendimento mais humanizado e com maior capacitação técnica às mulheres vítimas de violência doméstica e familiar. O Programa além de fiscalizar o cumprimento de medidas protetivas e promover visitas técnicas, o Promuse quando necessário, encaminha as atendidas pelo Programa para a rede de atendimento e apoio.
}

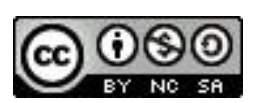




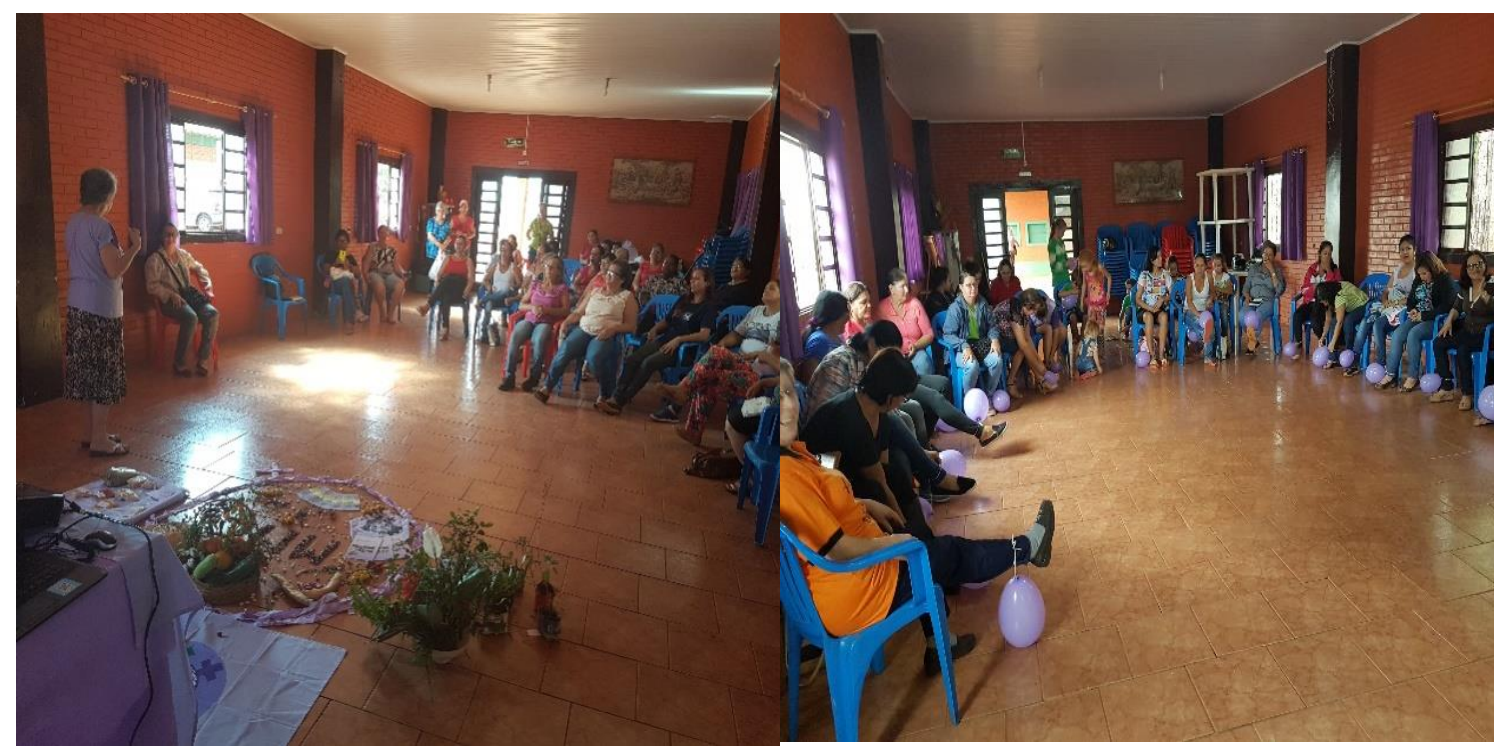

Fonte: Relatórios Fotográficos 2017

Fonte: Relatório Fotográfico 2018

A Roda de Conversa tem uma participação significativa da comunidade, com grande rotatividade de participantes, sobretudo, porque muitas integrantes atuam como multiplicadoras da Roda de Conversa nos seus espaços de moradia e convivências. Identificando assim, mulheres que se encontram em situação de violência e na maioria das vezes, desconhecendo as leis que asseguram o seu direito de viver sem violência. Nesses casos, a partir da solidariedade e do acolhimento, respeitando-se o devido tempo de cada mulher, essa mulher que se encontra em situação de violência vai integrando a Roda de Conversa, passando a conhecer a Rede de Enfrentamento a Violência Contra à Mulher, bem como seus direitos.

No espaço da Roda de Conversa, tem se pautado ainda, temáticas enfocando as questões de gênero, ampliando as discussões e reflexões em torno da valorização e do respeito pelo trabalho produtivo realizado pelas mulheres e da importância da participação nos espaços públicos, no sentido de se construir novas formas de pensar e agir para se transformar a realidade cotidiana.

A dinâmica metodológica da Roda de Conversa, conta ainda, com um momento denominado de alimento solidário, como mais uma forma de sociabilidade e acolhimento, este momento acontece através da cerimônia que é realizada através de um lanche que é

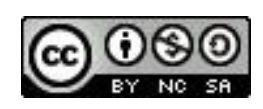


partilhado por todas que compõem a roda. Nesse contexto, a alimentação envolve outras dimensões para além do ato de se alimentar, conforme registra Boff (2009) que a partir do alimento, resgatamos elementos importantes que compõem a vida e que complementam as reflexões através do ato de compartilhar.

No espaço da Roda de Conversa as mulheres que estão vivenciando alguma forma de violência são acolhidas, sendo respeitado seu tempo para entender que há uma rede especializada para o enfrentamento à violência contra a mulher com atendimento multidisciplinar. Os dados coletados demonstram que a participação das mulheres do Assentamento Itamarati no espaço da Roda de Conversa vem gradativamente crescendo como pode ser verificado no gráfico 1 que ilustra o número de mulheres que participaram das atividades da Roda de Conversa nos anos de 2017 e 2018.

Mulheres Participantes da Roda de Conversa em 2017 e 2018

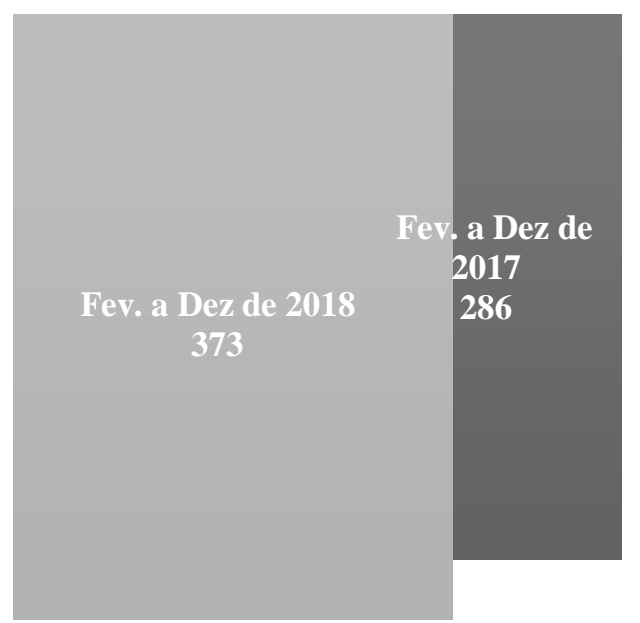

Figura 1: Frequência de Mulheres que participaram da Roda de Conversa em 2017 e 2018

Fonte: Listas de Presença das Rodas de Conversa, arquivadas na Agraer P.A Itamarati (2017, 2018).

A Roda de Conversa tem construído relações e ações no sentido do fortalecimento da luta e do enfrentamento à violência contra as mulheres, buscando a construção coletiva do reconhecimento e autoafirmação do direito de não sofrerem violência no espaço público ou privado, de serem respeitadas em suas especificidades com a garantia de acesso aos serviços da rede de enfrentamento à violência contra a 
mulher. As ações metodológicas buscam contribuir para o fortalecimento das mulheres e a para construção da igualdade de gênero.

Embora a temática da violência contra mulher tem chamado a atenção nos últimos anos, percebe-se que as mulheres que se encontram em situação de violência no meio rural, têm as dificuldades ampliadas, uma vez que, para ter acesso ao atendimento ofertado pela rede que compõe o Centro de Atendimento à Mulher (CAM), é necessário se deslocar para a cidade. Além disso, existe o medo e a insegurança para consigo e seus filhos e, muitas vezes, o recurso econômico está sob o domínio exclusivo do homem.

Considerando os fatores relacionados à distância e a dependência econômica, a Roda de Conversa, buscou construir em 2016 uma parceria com a Rede de Atendimento à Mulher (CAM) no sentido de se realizar atendimentos no próprio Assentamento, principalmente os psicológicos e jurídicos e os encaminhamentos para os demais atendimentos bem como, viabilizar os meios para o acesso. Em 2017 a parceria foi reafirmada com a nova gestão e segue com muito êxito. Entre os meses de fevereiro a dezembro no ano de 2017 foram realizados pela equipe do Centro de Atendimento (CAM) 16 (dezesseis) atendimentos psicológicos e 10 (dez) atendimentos jurídicos, descrito no gráfico 2 .

Atendimentos Psicológicos e Jurídicos/2017

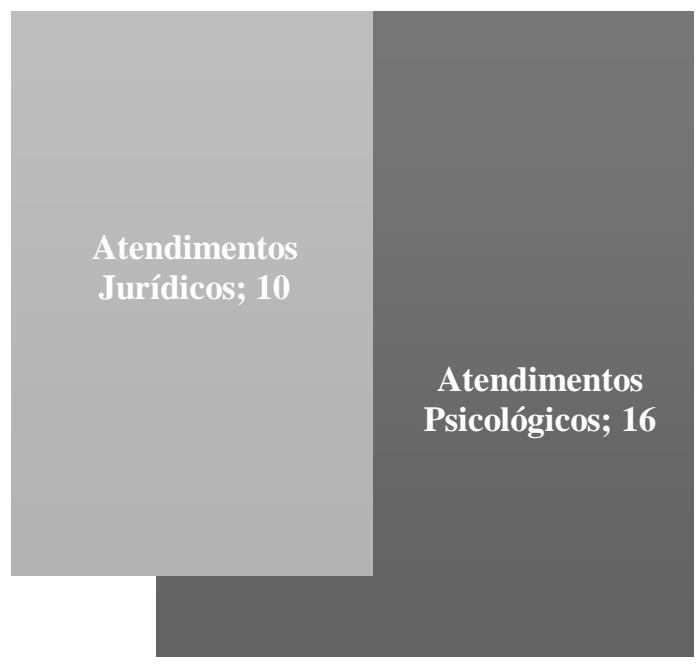

Figura 2: Número de Atendimentos Psicológicos e Jurídicos no ano de 2017. Fonte: CAM/Ponta Porã, MS, (2019). 
O atendimento psicológico é de suma importância para as mulheres vítimas de violência em função dos impactos que a violência causa tanto à saúde física e emocional quanto à autoestima, Hirigoyen (2006) enfatiza que a mulher em situação de violência tem seu estado psicológico e moral afetados profundamente pelo processo de desqualificação e de culpabilização. Dessa forma, o atendimento psicológico é de fundamental importância para que a mulher vítima de violência, compreenda-se enquanto sujeito e recupere sua autoestima e sua autonomia. O acompanhamento psicológico auxilia na construção de mecanismos que propiciem romper com realidade marcada pela violência e ainda, é fundamental para superar as sequelas deixadas.

Entre os meses de fevereiro a dezembro do ano de 2018 foram realizados 15 (quinze) atendimentos psicológicos e 12 (doze) atendimentos jurídicos, conforme registrado no gráfico 3. Gráfico 3:

Atendimentos Psicológicos e Jurídicos/2018

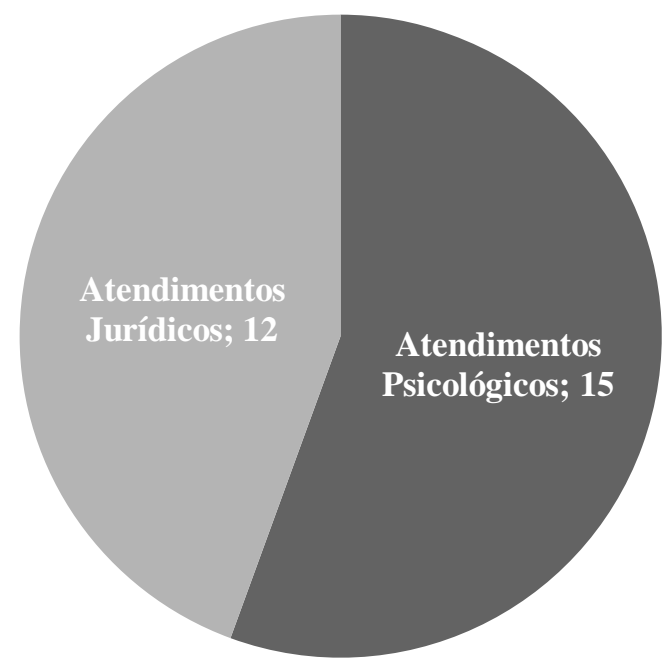

Figura 3: Descrição dos atendimentos Psicológicos e Jurídicos no ano de 2018 Fonte: CAM/Ponta Porã, MS, (2019)

$\mathrm{O}$ atendimento jurídico também é fundamental, principalmente para que a mulher vítima de violência tenha garantido o acesso à justiça, sobretudo, em relação às medidas protetivas que são necessárias, bem como a garantia aos direitos econômicos em caso de separação.

Os atendimentos jurídicos e psicológicos são realizados nas primeiras quartasfeiras dos meses de fevereiro a dezembro, no próprio Assentamento Itamarati, com 
acompanhamento a Defensoria Pública ou a Delegacia de Mulher, ou ainda, a casa de acolhimento quando se faz necessário. Os profissionais que fazem os atendimentos psicológico e jurídico são disponibilizados pela administração Municipal, assim como o deslocamento desses profissionais.

Os atendimentos psicológicos, jurídicos e a dinâmica da roda constituem-se em importantes canais de identificação e dissolução de inúmeros casos de violência praticada pelo parceiro, que as mulheres compartilharam durante a atividade, até então, nunca relatados por medo, constrangimento, sentimento de culpa, vergonha, isolamento, preocupação com julgamento da sociedade, enfim circunstâncias que favorecem o isolamento social e dificultam a ação dos serviços de apoio e proteção a mulher.

É oportuno destacar, a participação na Roda de Conversa das jovens, que são motivadas pelas mães, colegas e professoras que abordam a violência em sala de aula, ampliando assim, a relevância e as ações da Roda, para que não se limitem apenas ao espaço físico e ao encontro mensal. Esse processo emancipatório e fundamental para que possam posteriormente atuar como multiplicadoras dos conhecimentos adquiridos conscientizando e mobilizando a comunidade para denunciar todos os tipos de violência, propor e discutir mecanismos de proteção e prevenção com base na Lei Maria da Penha ${ }^{12}$.

As ações de enfrentamento e prevenção da violência contra à Mulher desenvolvidas pela Roda de Conversa do assentamento Itamarati desde 2015, proporcionou ao município de Ponta Porã/MS o recebimento do Selo Social ñPrefeitura Amiga da Mulherò O Selo Social é o reconhecimento e valorização de ações desenvolvidas nos eixos de enfrentamento à violência contra as mulheres e incentivo ao empreendedorismo feminino.

A Roda de Conversa tem contribuído para ampliar a participação das mulheres a outros espaços de luta e enfrentamento à violência contra à mulher em especial no ano de 201804 (quatro) integrantes da Roda participaram do Seminário Estadual ñEnfrentamento à Violência contra as Mulheresòrealizado pela Subsecretaria de Políticas Públicas para Mulheres do Estado de Mato Grosso do Sul no mês de agosto de 2018 em Campo Grande. E no mês de novembro de 201826 (vinte e seis) integrantes da Roda de

\footnotetext{
${ }^{12}$ A Lei 11.340/06, conhecida como Lei Maria da Penha, ganhou este nome em homenagem à Maria da Penha Maia Fernandes, que por vinte anos lutou para ver seu agressor preso. A Lei Maria da Penha é reconhecida e destacada pela ONU como uma das três melhores legislações do mundo no enfrentamento à violência contra as mulheres (BRASIL, 2012).
} 
Conversa participaram da Audiência Pública: ñAções de Enfrentamento à Violência Contra a Mulherò realizada pela Câmara Municipal de Ponta Porã/MS. A presença ativa das mulheres nas discussões em espaços públicos é fundamental para a luta contra a violência e sobretudo, para a emancipação e o fortalecimento das mulheres em direção às redefinições das relações de gênero no espaço da família, da produção e da comunidade.

\section{CONSIDERAÇÕES FINAIS}

A iniciativa da Roda de Conversa constitui-se em uma ferramenta de combate à violência contra a mulher no Assentamento Itamarati, pois essa é uma realidade muito presente dentro do assentamento, que apesar dos avanços, ainda é um tabu no sentido de enfrentamento. A metodologia da Roda de Conversa permite um processo educativo, dialógico, democrático e participativo no qual a comunidade é protagonista em sua construção e continuidade, trata-se de um espaço que envolve vários segmentos da sociedade representados por servidores públicos, militares, líderes e agentes comunitários, religiosos e demais moradores da comunidade. É justo e importante destacar a valiosa participação das mulheres/companheiras, que ao longo desses encontros tiveram suas vidas transformadas e que hoje continuam apoiando e fortalecendo a roda, para que outras mulheres tenham acesso às informações e aos espaços de diálogo e se libertem de quaisquer tipos de violência.

As mulheres do assentamento que vivenciam situações de violência, além das barreiras históricas, culturais e sociais impostas que limitam o enfrentamento, ainda encontram a dificuldade da distância entre o assentamento e a rede que proporciona o atendimento psicossocial, aconselhamento e acompanhamento, jurídico e demais encaminhamentos necessários, que se localiza no município de Ponta Porã.

Nesse sentido, a parceria da Roda de Conversa com a Centro de Atendimento à Mulher (CAM) veio sanar a dificuldade da distância, uma vez, que os atendimentos psicológicos e jurídicos são realizados dentro do próprio assentamento com agendamento prévio. A Roda de Conversa tem se configurado ainda, como instrumento de contato com

o Centro de Atendimento à Mulher, no sentido de solicitar visitas in loco tanto para verificação quanto para apoio em casos de violência. 
As mulheres que participam da Roda de Conversa atuam como elo de contato nas suas comunidades. Quando há indícios de alguma forma de violência a vítima é convidada de forma discreta para participar da Roda de Conversa e conhecer a rede de enfrentamento à violência contra a mulher. A Roda de Conversa conta ainda, com apoio de profissionais de diversas áreas com conhecimentos que contribuem para a fortalecimento das mulheres para que possam buscar atendimento sair do ciclo de violência.

$\mathrm{Na}$ Roda de Conversa, as mulheres são acolhidas e incentivadas a protagonizarem sua história, livre de quaisquer tipos de violência. A Roda de Conversa é uma iniciativa que nasceu na comunidade e se consolidou em função da efetiva participação e o comprometimento das mulheres buscando dar um basta na violência contra às mulheres no Assentamento Itamarati.

\section{REFERÊNCIAS}

ASSOCIAÇÃO NACIONAL DE MULHERES CAMPONESAS. Mulheres Camponesas: Caminhando rumo à superação da violência. Cartilha. Maio de 2008.

BRASIL. Ministério Público do Distrito Federal. Núcleo de Gênero da Coordenação dos Núcleos de Direitos Humanos. Mulher, Valorize-se:Conscientize-se de seus direitos. [s.l]: Núcleo de gênero da coordenação dos direitos humanos, 2012.

BOFF, L. ñComensalidade: refazer a humanidadeò. Jornal A Notícia, Joinville, 19 abr. 2009.

CHAUÍ, M. ñParticipando do Debate sobre Mulher e Violênciaò. In: FRANCHETTO, B, Cavalcanti, M. L. V. C; Heilborn, M. L. (org.). Perspectivas Antropológicas da Mulher 4, São Paulo, Zahar Editores, 1984.

FUNDAÇÃO CANDIDO RONDON. Plano de Desenvolvimento de Assentamento. Projeto de Assentamento Itamarati, II. Campo Grande Ï MS, 2006.

FREIRE P. Pedagogia da autonomia: saberes necessários à prática pedagógica. São Paulo:

Paz e Terra; 1996.

GIL, A. C. Como elaborar projetos de pesquisa. 5. ed. São Paulo: Atlas, 2010. 184p.

HIRIGOYEN, M. F. A Violência no Casal: da coação psicológica à agressão física. Rio de Janeiro: Bertrand Brasil, 2006 
MACHADO, L. Z. Perspectivas em confronto: Relações de Gênero ou Patriarcado Contemporâneo? Série antropologia, 284. Brasileia: Instituto de Ciências Sociais/Universidade de Brasília, 2000.

MENEGAT, A. S. Mulheres de assentamentos rurais: identidades e trajetórias em construção. In: SEMINÁRIO INTERNACIONAL FAZENDO GÊNERO: corpo, violência e poder, 8. 2008, Florianópolis. Anais.... Florianópolis: Mulheres, 2008. Disponível em:

<Http://www.fazendogenero.ufsc.br/8/sts/ST17/Alzira_Salete_Menegat_17.pdf> Acesso em: 18 de out. 2019.

MMC. Basta de violência contra as mulheres. Brasília, DF, 2012

MMC. Feminismo Camponês e Popular. Cartilha, 2018.

MATO GROSSO DO SUL. Secretaria de Estado de desenvolvimento agrário (SDA). Instituto de desenvolvimento agrário, assistência técnica e Extensão rural do MS (IDATERRA). Plano de Desenvolvimento do Assentamento Itamarati: Produção. 2003.

PALUDO, C. Mulheres, resistência e luta em defesa da vida. (Org.) PALUDO, C. São Leopoldo: CEBI. 2009. $171 \mathrm{p}$. 